\title{
Analysis of electromigration phenomenon in thick-film and LTCC structures at elevated temperature*
}

\author{
Damian NowaK ${ }^{\dagger}$, ANDrZEJ STAFIniak, ANDRZEJ DZIEDZIC \\ Faculty of Microsystem Electronics and Photonics, Wroclaw University of Technology, \\ Wybrzeże Wyspiańskiego 27, 50-370 Wrocław, Poland
}

\begin{abstract}
Studies on electromigration phenomenon in thick-film structures on alumina and LTCC substrates are presented in this paper. The effects of storage of $\mathrm{Au}$ and $\mathrm{Ag}$ electrode patterns in temperature range up to $300{ }^{\circ} \mathrm{C}$ under voltage bias were examined. The leakage characteristics of electrodes with $100 \mu \mathrm{m}$ spacing at $50 \mathrm{~V} \mathrm{dc}$ bias as a function of time and temperature are presented and analyzed. Scanning electron microscope (SEM) equipped with the energy-dispersive X-ray spectroscopy (EDX) detector was applied for determination of metal ions transport. Test structures with Au-based conductive material are much more resistant to electromigration than Ag-based layers.
\end{abstract}

Keywords: LTCC; thick-film; electromigration; reliability

(C) Wroclaw University of Technology.

\section{Introduction}

Consumer electronics with typical operating environments of $-40{ }^{\circ} \mathrm{C}$ to $+85^{\circ} \mathrm{C}$ is the largest electronics market segment. A small group of specialized components complies with requirements for application in the temperature range from $-55^{\circ} \mathrm{C}$ to $+125^{\circ} \mathrm{C}$. However, an increasing interest in the field of high temperature electronics has been observed for recent years [1] and there are applications for electronics that operate at much higher temperatures. These include: distributed controls for automotive and aircraft, oil and gas exploration and production, industrial processes control or even space exploration [2,3]. Thick-film and LTCC (Low Temperature Cofired Ceramics) technologies are well-established fabrication methods of microelectronic circuits. They utilize conductive pastes to interconnect different discrete device on a common substrate. However, a metal inclusion component in conductive pastes might be susceptible to electromigration phenomenon that affects

\footnotetext{
*This paper was presented at the $37^{\text {th }}$ International Microelectronics and Packaging Conference IMAPS-CPMT Poland 2013, 22 - 25 September 2013, Kraków.

†E-mail: damian.nowak@pwr.edu.pl
}

reliability of such electronic circuits [4-6]. The metallic electromigration is defined as the movement of metallic material, usually through or across a nonmetallic medium, under the influence of an electrical field. Two basic types of electromigration are observed. The first one is an electrochemical (ionic) migration that takes place under normal ambient conditions in presence of moisture on a surface. The second type is solid-state electromigration that becomes important at local temperatures above $150{ }^{\circ} \mathrm{C}$ and at high current densities. Thus, high temperature exploitation of thick-film and LTCC circuits requires recognition of potential failure processes. This paper presents characterization of the effects of high temperature storage under dc bias, which occur in thick-film conductor patterns made of commercially available thick-film and LTCC materials.

\section{Test structures}

The test structures used for investigation of electromigration were made using a combination of standard screen-printing with laser shaping [7, 8]. The electrodes were made on alumina or LTCC (DP951 tape, DuPont) substrates. The four different electrode shapes (Fig. 1) were created by 
laser cutting of Ag-based (DP6145, DuPont) or Aubased (ESL8844, ElectroScience Lab.) conductive layers. The minimal distance between electrodes was equal to $100 \mu \mathrm{m}$. Frequency-tripled Nd:YAG laser (wavelength of $355 \mathrm{~nm}$ ) - ProtoLaser U system (LPKF, Germany) was used for this purpose. Next the samples were fired in a belt furnace with a standard temperature profile $\left(T_{\max }=850{ }^{\circ} \mathrm{C}\right.$, total firing time $t=60$ minutes).

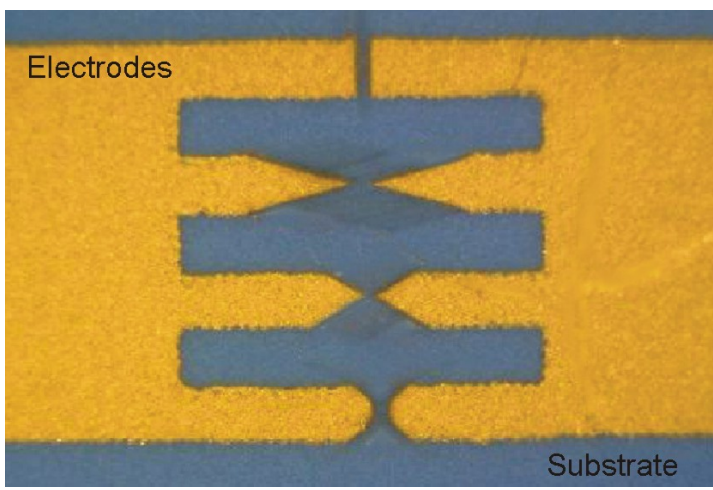

Fig. 1. Test structures with different shapes of electrodes (gold color - conductive material, blue substrate).

\section{Investigation and results}

The fired structures have been observed with Hitachi SU6600 scanning electron microscope (Fig. 2 and 3) and AxioCam MR5 (Zeiss) optical microscope. The grain structure with many pores is visible. Both $\mathrm{Au}$ and $\mathrm{Ag}$ grains have dimensions of several micrometers. Additionally, an EDX (Energy-Dispersive X-ray Spectroscopy) was performed on chosen areas of the structure. The elemental analysis of the samples exhibited presence of standard materials used in thick-film composition (Table 1) i.e. metal ( $\mathrm{Ag}, \mathrm{Au}$ ) from active phase and aluminium, oxygen, silicon or lead, mainly from glass phase but also probably from the substrates. One should be noticed that the presence of $\mathrm{Na}$ and $\mathrm{Ca}$ ions especially in substrate material might be a reason for higher leakage current at elevated temperature.

A very good removal of conductive material was observed by laser processing. However, a

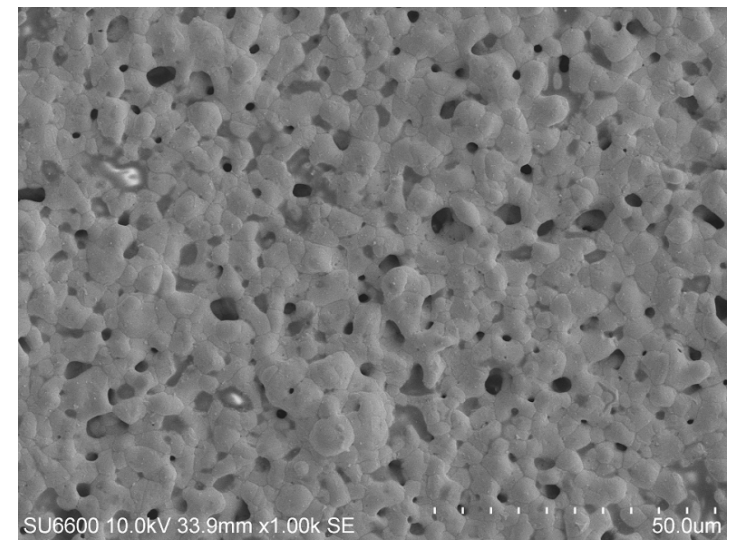

Fig. 2. Scanning electron micrograph of thick-film silver layer (magnification $1000 \times$ ).

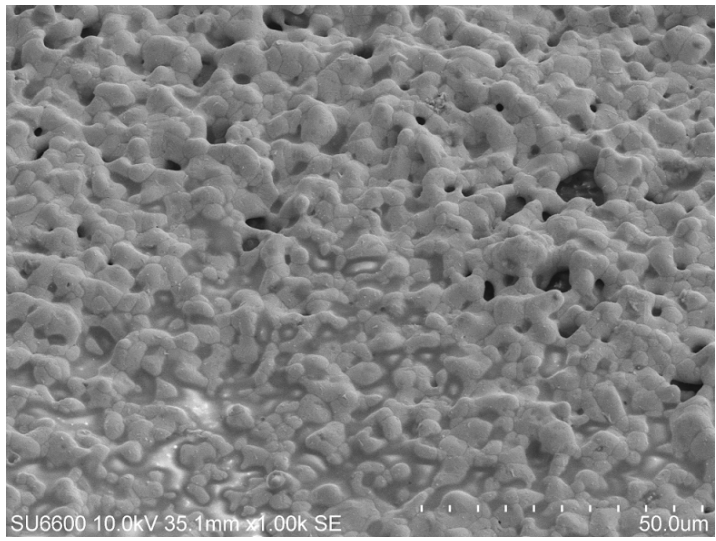

Fig. 3. Scanning electron micrograph of thick-film gold layer (magnification $1000 \times$ ).

clearly visible damage of substrate material occurred due to laser ablation, both on alumina and LTCC substrate (Fig. 4).

After microstructure analysis the test structures have been subjected to thermal ageing process. The samples were placed on a hot plate (Microtherm SHP-500) equipped with a PID temperature controller. Each structure was wired to laboratory power supply through a series resistor $R=100 \mathrm{k} \Omega$ (Fig. 5) in order to limit the current in case of shorted structure as well as to allow monitoring the leakage current for each pattern. The Agilent 34970A multimeter was used for measurements of voltage drop across the series resistor. The measurements were carried out consecutively at $200{ }^{\circ} \mathrm{C}$ and $300{ }^{\circ} \mathrm{C}$ for about 160 and 250 hours under 
Table 1. Elemental analysis of conductive films (wt.\%).

\begin{tabular}{lcccccccc}
\hline & $\mathrm{Ag}$ & $\mathrm{Au}$ & $\mathrm{O}$ & $\mathrm{Al}$ & $\mathrm{Si}$ & $\mathrm{Na}$ & $\mathrm{Ca}$ & $\mathrm{Pb}$ \\
\hline \hline DP6145/LTCC & 89.47 & - & 6.96 & 0.57 & 1.37 & 0.23 & 0.25 & - \\
ESL8844/LTCC & - & 89.79 & 2.60 & 0.43 & - & 0.53 & - & 2.52 \\
\hline
\end{tabular}

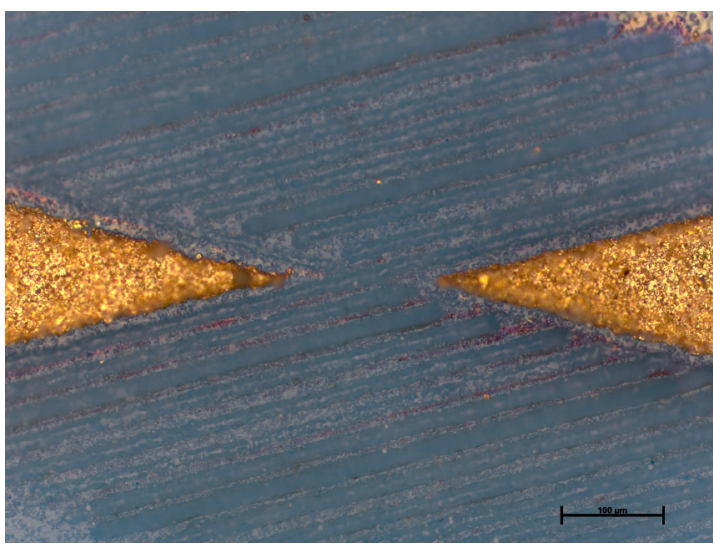

Fig. 4. Gold conductor on LTCC substrate (magnification $100 \times)$.

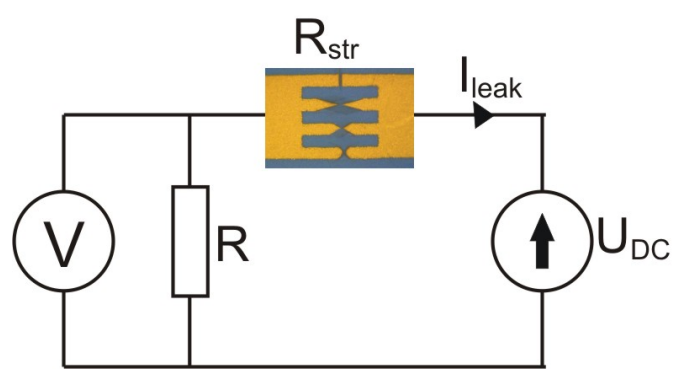

Fig. 5. Scheme of the test set-up for leakage current measurements.

$50 \mathrm{~V}$ dc bias. Data were collected every 10 minutes. Fig. 6 presents the changes in leakage current for Ag-based test structures at different temperatures, whereas the resistance of investigated structures, calculated from the formula $R_{s t r}=U_{D C} / I_{\text {leak }}-R$, is shown in Fig. 7. After 106 hours at $200{ }^{\circ} \mathrm{C}$ a significant increase of leakage current was observed for silver electrodes on alumina substrate. At temperature of $300{ }^{\circ} \mathrm{C}$ an increase of current to $420 \mu \mathrm{A}$ just after 3 hours was observed for silver on LTCC substrate. Within next 4 hours it raised up to $470 \mu \mathrm{A}$.

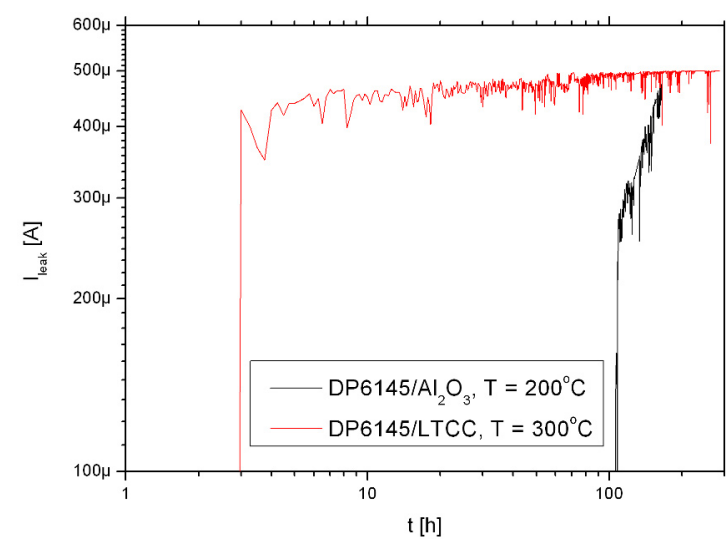

Fig. 6. Leakage current between Ag-based electrodes $v s$. time at different temperatures.

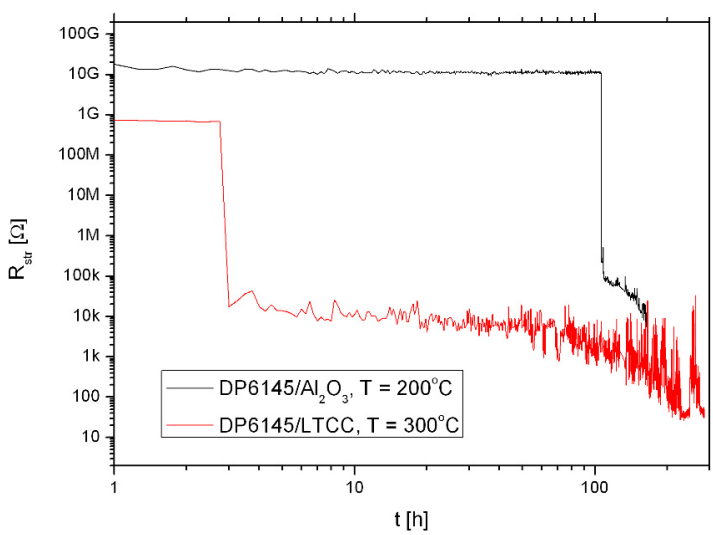

Fig. 7. Resistance of the structure $v s$. time at different temperatures.

No changes in leakage current under presented test conditions have been observed for structures with gold electrodes. Table 2 presents comparison of leakage current tests.

\section{Failure analysis}

Scanning electron microscope has been applied again for determination of failure mechanism in the 
Table 2. Comparison of leakage current test results.

\begin{tabular}{lll}
\hline Structure & Test conditions & Leakage current \\
\hline \hline DP6145/Al ${ }_{2} \mathrm{O}_{3}$ & $\mathrm{U}=50 \mathrm{~V}, \mathrm{~T}=200{ }^{\circ} \mathrm{C}, \mathrm{t}=160 \mathrm{~h}$ & $\begin{array}{l}\mathrm{I}_{(t=106 h)}=140 \mu \mathrm{A} \nearrow \\
\mathrm{I}_{(t=110 h)}=430 \mu \mathrm{A}\end{array}$ \\
\hline DP6145/LTCC & $\mathrm{U}=50 \mathrm{~V}, \mathrm{~T}=200{ }^{\circ} \mathrm{C}, \mathrm{t}=160 \mathrm{~h}$ & $\mathrm{I}<1 \mu \mathrm{A}$ \\
\hline DP6145/LTCC & $\mathrm{U}=50 \mathrm{~V}, \mathrm{~T}=200{ }^{\circ} \mathrm{C}, \mathrm{t}=160 \mathrm{~h}+$ & $\mathrm{I}_{(t=3 h)}=420 \mu \mathrm{A} \nearrow$ \\
& $\mathrm{U}=50 \mathrm{~V}, \mathrm{~T}=300{ }^{\circ} \mathrm{C}, \mathrm{t}=250 \mathrm{~h}$ & $\mathrm{I}_{(t=7 h)}=470 \mu \mathrm{A}$ \\
\hline ESL8844G/Al $\mathrm{O}_{3}$ & $\mathrm{U}=50 \mathrm{~V}, \mathrm{~T}=200{ }^{\circ} \mathrm{C}, \mathrm{t}=160 \mathrm{~h}+$ & $\mathrm{I}<1 \mu \mathrm{A}$ \\
& $\mathrm{U}=50 \mathrm{~V}, \mathrm{~T}=300{ }^{\circ} \mathrm{C}, \mathrm{t}=250 \mathrm{~h}$ & \\
\hline ESL8844G/LTCC & $\mathrm{U}=50 \mathrm{~V}, \mathrm{~T}=200{ }^{\circ} \mathrm{C}, \mathrm{t}=160 \mathrm{~h}+$ & $\mathrm{I}<1 \mu \mathrm{A}$ \\
& $\mathrm{U}=50 \mathrm{~V}, \mathrm{~T}=300{ }^{\circ} \mathrm{C}, \mathrm{t}=250 \mathrm{~h}$ & \\
\hline
\end{tabular}

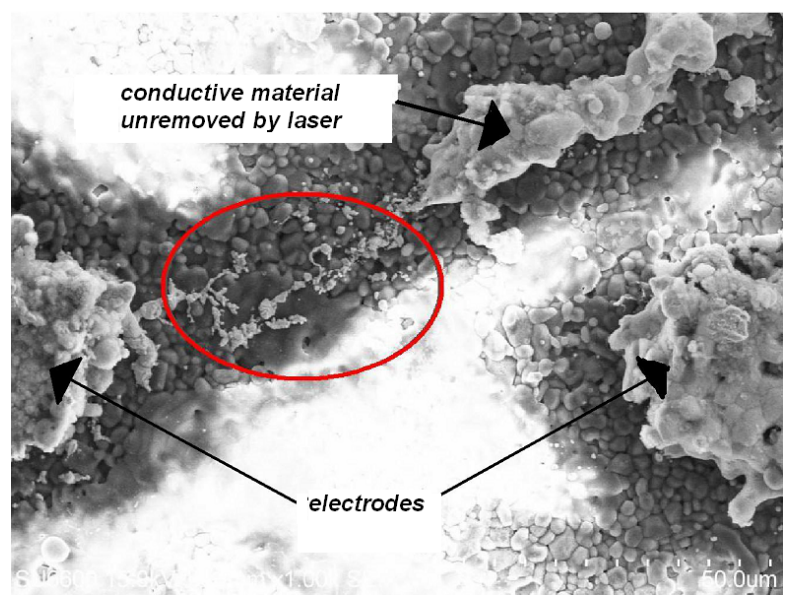

Fig. 8. Conductive path between silver electrodes on $\mathrm{Al}_{2} \mathrm{O}_{3}$ substrate.

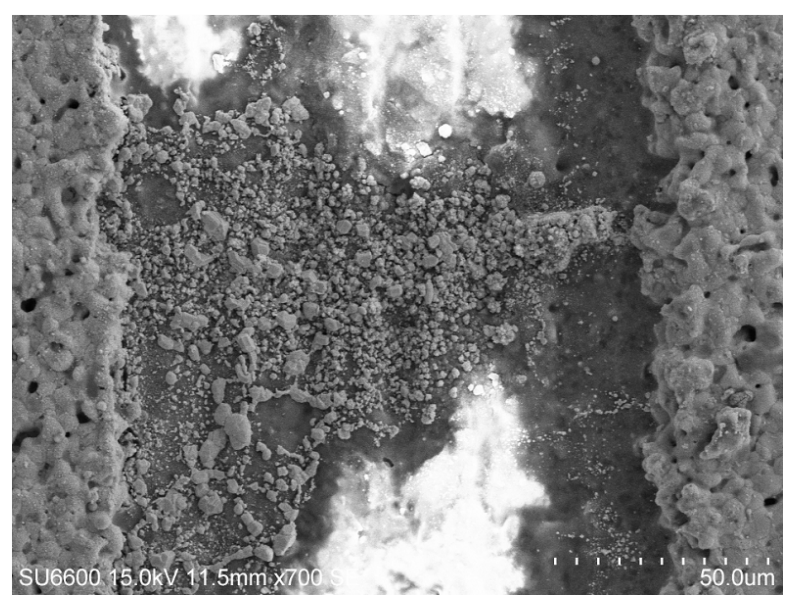

Fig. 9. Conductive path between silver electrodes on LTCC substrate.

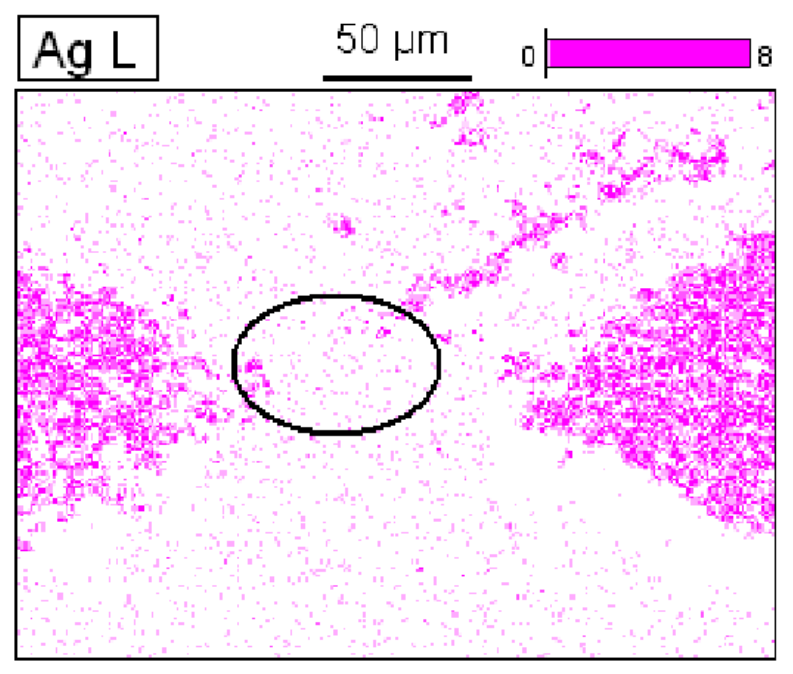

Fig. 10. Silver electrodes on $\mathrm{Al}_{2} \mathrm{O}_{3}$ substrate (EDX mapping).

test structures. The micrographs made previously were compared to those after ageing tests. In Fig. 8 and 9 scanning electron micrographs of the samples are presented where an increase of leakage current had occurred. In both of them a conductive path was created due to solid-state electromigration process i.e. transport of material caused by the gradual movement of the ions in a conductor due to the momentum transfer between conducting electrons and diffusing metal atoms. The mean time to failure for electromigration process is modelled as

$$
M T T F=\frac{A}{j^{n}} \exp \left(\frac{E_{a}}{k T}\right)
$$




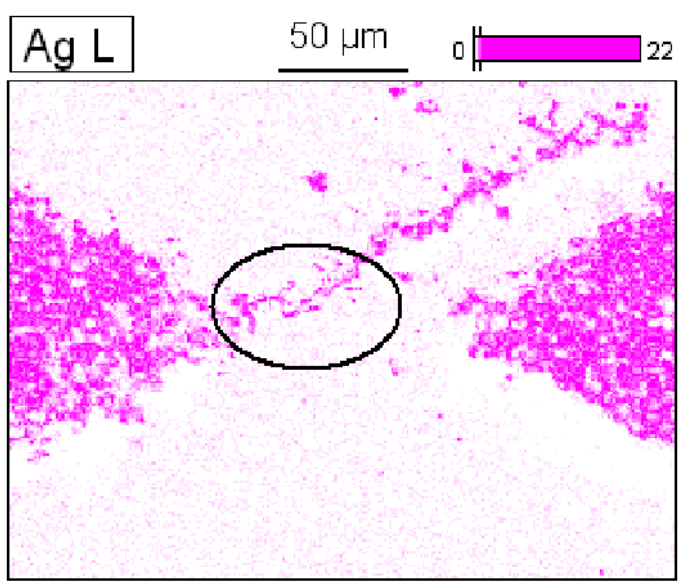

Fig. 11. Silver electrodes on $\mathrm{Al}_{2} \mathrm{O}_{3}$ substrate after ageing at $200{ }^{\circ} \mathrm{C}$ under $50 \mathrm{~V}$ dc bias (EDX mapping).

where $A$ is a constant which comprises the material properties and the geometry of the interconnect, $j$ is current density, $n$ is a model parameter for current density, $E_{a}$ is the activation energy, $k$ is Boltzmann's constant, and $T$ is the temperature [9]. The current density is the largest for V-shaped electrodes, therefore electromigration appears faster near these electrodes (Fig. 8). After creation of first shortcut connection between electrodes the leakage current intensity increased causing even more effective transport of ions.

EDX analysis has been used to determine the presence of mobile ions and the elemental analysis confirmed that conductive paths have been created by silver ions. Element maps before and after ageing test are presented in Fig. 10 and 11.

\section{Conclusions}

Two thick-film conductors have been evaluated for $300{ }^{\circ} \mathrm{C}$ applications. High temperature biased ageing identified a failure mechanism. A creation of conductive path (shortcuts) due to solid-state electromigration process has been observed in case of silver-based films. Temperature level had a significant influence on intensity of ions transport.

\section{Acknowledgements}

This work was supported by the National Science Centre (Poland), Grant DEC-2011/01/B/ST7/06564.

\section{References}

[1] Johnson R., Evans J.L., Jacobsen P., Thompson J.R. Christopher M., IEEE T. Electron. Pa. M., 27 (2004), 164.

[2] Neudeck P., Okojie R., Chen L.-Y., P. IEEE, 90 (2002), 1065.

[3] Buttay C. et al., Mat. Sci. Eng. B-Solid, 176 (2011), 283.

[4] Naguib H., Maclaurin B., IEEE T. Compon. Hybr., 2 (1979), 196.

[5] Krumbein S.J., IEEE T. Compon. Hybr., 11 (1989), 5.

[6] Zhang R., Johnson R.W., Vert A., Zhang T., SHADDOCK D., IEEE T. Compon. Hybr., 2 (2012), 1750.

[7] Miś E., Borucki M., Dziedzic A., KAMiński S., Wolter K.-J., Sonntag F., ESTC 2006, 954.

[8] NowaK D., Miś E., Dziedzic A., Kita J., Microelectron. Reliab., 49 (2009), 600.

[9] Orio R., CERIC H., SElberher S., Microelectron. Reliab., 52 (2012), 1981. 